\title{
Adverse effects of the consumption of artificial sweeteners - systematic review
}

\section{EFEITOS ADVERSOS DO CONSUMO DE ADOÇANTES ARTIFICIAIS - REVISÃO SISTEMÁTICA}

Bernardo WM ${ }^{1}$, Simões RS ${ }^{1}$, Buzzinı RF ${ }^{1}$, Nunes VM ${ }^{1}$, Glina FPA ${ }^{1}$

${ }^{1}$ Guidelines Project, Associação Médica Brasileira

\section{ОвJective}

Guide health professionals and the general public about the use of artificial sweeteners and their consequences for health.

\section{Methodology}

\section{Inclusion and exclusion criteria}

Studies that evaluated adults and children who used artificial sweeteners compared with individuals who did not were included. As outcome, the adverse clinical effects of this association were analyzed.

Exclusion criteria were non-epidemiological and noncomparative studies, and those in disagreement with the inclusion criteria.

\section{Databases}

The following databases and respective searches were used.

- Medline/PubMed: (Sweetening Agents/adverse effects OR Saccharin OR Cyclamate* OR Aspartame OR Acetosulfame OR Acesulfame) AND (Risk Factors OR Risk OR Risk Assessment OR Neoplasm* OR Carcinoma OR Cancer OR Carcinogenic) AND (Etiology/Broad[filter] OR Prognosis/Broad[filter] OR Comparative study OR Comparative studies).

- Embase: 'saccharin'/exp OR saccharin OR cyclamate* OR 'aspartame'/exp OR aspartame OR acetosulfame OR 'acesulfame'/exp OR acesulfame AND ('risk') $\exp$ OR risk AND factors OR 'risk'/exp OR risk AND assessment OR neoplasm* OR 'carcinoma'/exp OR carcinoma OR 'cancer'/exp OR cancer OR carcinogenic) AND ('controlled study'/de OR 'human'/de).

- Cochrane Library: '(Sweetening Agents OR Saccharin OR Cyclamate OR Aspartame OR Acetosulfame OR Acesulfame) in title abstract keywords in Trials'.

- Lilacs/Scielo: (Sweetening Agents OR Saccharin OR Cyclamate OR Aspartame OR Acetosulfame OR Acesulfame).

\section{Critical assessment}

The evidence retrieved was selected from critical evaluation ${ }^{1,2}$ (D) using as discriminatory instrument (score) the New
Castle Ottawa Scale ${ }^{3}(\mathbf{D})$ for observational studies. After defining the potential studies, these were classified by strength of evidence and grade of recommendation according to the Oxford classification, ${ }^{4}(\mathbf{D})$ including the strongest evidence available.

\section{ResULTS}

453 articles were retrieved from Medline, 523 from Embase, 510 from Cochrane Library, and 99 from Lilacs/Scielo. 40 articles were selected by reading the title and abstract. After reading the full text, 14 studies were selected.

\section{Analysis}

Pregnant women

A study including 59.334 pregnant women evaluated the association between intake of artificially-sweetened or sucrose-sweetened soft drinks, carbonated or not, and the birth of preterm (< 37 weeks) infants as the primary endpoint. This association was confirmed with $\mathrm{p} \leq 0.001$ for both variables. In the comparison with pregnant women who did not consume sweetened soft drinks, the adjusted odds ratio (OR) for the women consuming one or more units of sweetened carbonated soft drink per day was $1.38(95 \mathrm{CI}=1.15-1.65)$; for those consuming $\geq$ 4 units/day, the OR was $1.78(95 \mathrm{CI}=1.19-2.66) .^{5}(\mathrm{~B}) \mathrm{Re}-$ inforcing these data, a study linked the high intake of artificially-sweetened drinks with prematurity; the adjusted OR for those who drank > 1 serving/day was 1.11 $(95 \mathrm{CI}=1.00-1.24){ }^{6}{ }^{6}(\mathbf{B})$

Another group of pregnant women $(60,466)$ was evaluated for intake during pregnancy of artificially-sweetened drinks in relation to childhood asthma and allergic rhinitis. In 18 months, it was found that mothers who consumed more artificially-sweetened noncarbonated drinks were more likely $(\mathrm{OR}=1.23 ; 95 \mathrm{CI}=1.13$ to 1.33$)$ to report a diagnosis of asthma in their children, compared to consumers of sugar-sweetened beverages. Similarly, mothers who consumed artificially-sweetened carbonated drinks had a greater chance of having a child diagnosed with asthma at age $7(\mathrm{OR}=1.30 ; 95 \mathrm{CI}=1.01-1.66)$, which was not 
found for self-reported allergic rhinitis $(\mathrm{OR}=1.31 ; 95 \mathrm{CI}=$ 0.98 - 1.74). These associations were not found with the use of sugar-sweetened beverages. ${ }^{7}$ (B)

\section{Type 2 diabetes}

To evaluate the association of type 2 diabetes (T2D) with intake of sugar-sweetened or artificially-sweetened drinks, a study included healthy men $(\mathrm{n}=40.389)$ and found 2,680 cases of type 2 diabetes within 20 years. Artificially-sweetened drinks were not associated with T2D, after multivariate analysis (adjusted) $[\mathrm{HR}=1.09 ; 95 \mathrm{CI}=0.98$ $1.21 ; \mathrm{p}=0.13) .^{8}(\mathbf{B})$

\section{Cancer}

In order to evaluate the relationship between the consumption of aspartame and the incidence of hematopoietic cancer and brain cancer, a study selected 340,045 men and 226,945 women. After excluding other participants ( $n=473.984)$, the population was followed for 5 years, with histological confirmation for hematopoietic cancers $(\mathrm{n}=1888)$ and brain cancers $(\mathrm{n}=315)$. There was no association between the intake of high levels of aspartame and risk of hematopoietic cancer ( $R R$ for $\geq 600 \mathrm{mg} /$ day $=$ 0.98 ; $95 \mathrm{CI}=0.76-1.27)$, glioma $(\mathrm{RR}$ for $\geq 400 \mathrm{mg} / \mathrm{day}=$ $0.73 ; 95 \mathrm{CI}=0.46-1.15 ; \mathrm{p}=0.05$ [inverse linear trend]), or their subtypes in both men and women. ${ }^{10}(\mathbf{B})$

Another epidemiological study included two cohorts to prospectively evaluate if the consumption of soft drinks containing aspartame or sugar is associated with the risk of hematopoietic cancers. When the data for males and females from both cohorts were combined, there was an increased risk of leukemia for consumption $\geq 1$ unit of diet soda per day $(\mathrm{RR}=1.42 ; 95 \mathrm{CI}=1.00-2.02) .{ }^{9}(\mathbf{B})$ Chance cannot be excluded from these results due to the inconsistent effect of gender. ${ }^{11}(\mathbf{B})$

Assessing the maternal consumption of aspartame during pregnancy or breastfeeding, the risk of brain tumor was investigated. 56 cases of brain tumor in children and 94 controls matched for age and gender were evaluated. There was no association between aspartame consumption by both the mother and the child and the risk of brain tumor development (OR with 95CI containing the unit for all comparisons) ${ }^{12}$ (B) A second study, which included 315 mothers of children with medulloblastoma diagnosed before 6 years of age and 315 mothers of control children, also found no association between aspartame consumption during pregnancy and the risk of brain tumor. ${ }^{13}(\mathbf{B})$ There is no association between glioma and aspartame consumption in adults. ${ }^{10}(\mathbf{B})$
Data from extensive investigations on the possibility of neurotoxic effects of aspartame, in general, do not support the hypothesis that aspartame in the human diet will affect nervous system function, learning and behavior. ${ }^{14}$ (A)

An Italian study, including as cases patients hospitalized for various types of cancers and as controls ( $\mathrm{n}=$ $7,028)$ patients with hospitalization for non-neoplastic acute illness, compared the association between consumption of sugar or artificial sweeteners, especially aspartame, and the development neoplasms. There was no association between the use of artificial sweeteners and cancer of the oral cavity, pharynx, esophagus, stomach, colon, rectum, endometrium and prostate. Regarding ovarian tumor, only the use of saccharin decreased the chance of occurrence. ${ }^{15,16}$ (B)

Evaluating the association between consumption of sugar and other artificial sweeteners, particularly aspartame, there was no relationship with the development of kidney tumor. For sugar, the adjusted OR was 0.79 (95CI $=0.49-1.28)$ and for other sweeteners, especially aspartame, the adjusted OR was $1.03(95 \mathrm{CI}=0.73-1.46) .{ }^{15}(\mathbf{B})$

In humans, a study of 7655 cases showed no association between the consumption of artificial sweeteners and bladder cancer $(\mathrm{RR}=0.97 ; 95 \mathrm{CI}=0.92-1.04) \cdot{ }^{17}(\mathbf{B})$

Infertility

Including 405 cases of clinically-defined infertility (30 50 years) and 379 controls, the relation between cyclamate or its metabolite cyclohexylamine and male fertility was assessed. No evidence was found of a significant association between the consumption of cyclamate and male infertility. ${ }^{18}(\mathbf{B})$

\section{EVIDENCE SUMMARY}

1. Daily consumption of artificially-sweetened soft drinks by pregnant women can increase the likelihood of prematurity.

2. The consumption of artificially-sweetened drinks by pregnant women may be associated with the diagnosis of asthma in their children up to the age of 7 years.

3. There is no association between aspartame consumption during pregnancy, lactation or by the child and brain tumor in childhood and adulthood.

4. There is no association between aspartame consumption and risk of hematopoietic cancer.

5. There is no association between the consumption of sugar or other sweeteners, particularly aspartame, and the development of cancer in the digestive and reproductive systems. 
6. Consumption of artificial sweeteners is not associated with the development of kidney or bladder cancer in humans.

7. The association between intake of artificially-sweetened drinks and type 2 diabetes is uncertain.

8. There is no association between the consumption of cyclamate and male infertility.

\section{RefEREnCES}

1. Nobre MR, Bernardo WM, Jatene FB. A prática clínica baseada em evidências. Parte I - Questões clínicas bem construídas. Rev Assoc Med Bras. 2003; 49(4):445-9.

2. Bernardo WM, Nobre MR, JateneFB. A prática clínica baseada em evidências. Parte II - Questões clínicas bem construídas. Rev Assoc Med Bras. 2004; 50(1):104-8.

3. Wells GA, Shea B, O'Connell D, Peterson J, Welch V, Losos M, et al. The Newcastle-Ottawa Scale (NOS) for assessing the quality of nonrandomized studies in meta-analyses. Available from: http://www.ohri.ca/programs/ clinical_epidemiology/oxford.asp

4. Levels of Evidence and Grades of Recommendations - Oxford Centre for Evidence-Based Medicine. Available from: www.cebm.net.

5. Halldorsson TI, Strøm M, Petersen SB, Olsen SF. Intake of artificially sweetened soft drinks and risk of preterm delivery: a prospective cohort study in 59,334 Danish pregnant women. Am J Clin Nutr. 2010; 92(3):626-33.

6. Englund-Ögge L, Brantsæter AL, Haugen M, Sengpiel V, Khatibi A, Myhre $\mathrm{R}$, et al. Association between intake of artificially sweetened and sugarsweetened beverages and preterm delivery: a large prospective cohort study. Am J Clin Nutr. 2012; 96(3):552-9.

7. Maslova E, Strøm M, Olsen SF, Halldorsson TI. Consumption of artificiallysweetened soft drinks in pregnancy and risk of child asthma and allergic rhinitis. PLoS One. 2013; 8(2):e57261.

8. de Koning L, Malik VS, Rimm EB, Willett WC, Hu FB. Sugar-sweetened and artificially sweetened beverage consumption and risk of type 2 diabetes in men. Am J Clin Nutr. 2011; 93(6):1321-7.
9. Fagherazzi G, Vilier A, Saes Sartorelli D, Lajous M, Balkau B, Clavel-Chapelon F. Consumption of artificially and sugar-sweetened beverages and incident type 2 diabetes in the Étude Épidémiologique auprès des femmes de la Mutuelle Générale de l'Education Nationale - European Prospective Investigation into Cancer and Nutrition cohort. Am J Clin Nutr. 2013; 97(3):517-23.

10. Lim U, Subar AF, Mouw T, Hartge P, Morton LM, Stolzenberg-Solomon R et al. Consumption of aspartame-containing beverages and incidence of hematopoietic and brain malignancies. Cancer Epidemiol Biomarkers Prev. 2006; 15(9):1654-9.

11. Schernhammer ES, Bertrand KA, Birmann BM, Sampson L, Willett WC, Feskanich D. Consumption of artificial sweetener- and sugar-containing soda and risk of lymphoma and leukemia in men and women. Am J Clin Nutr. 2012; 96(6):1419-28.

12. Gurney JG, Pogoda JM, Holly EA, Hecht SS, Preston-Martin S. Aspartame consumption in relation to childhood brain tumor risk: results from a casecontrol study. J Natl Cancer Inst. 1997; 89(14):1072-4.

13. Bunin GR, Kushi LH, Gallagher PR, Rorke-Adams LB, McBride ML, Cnaan A. Maternal diet during pregnancy and its association with medulloblastoma in children: a children's oncology group study (United States). Cancer Causes Control. 2005; 16(7):877-91.

14. Magnuson BA, Burdock GA, Doull J, Kroes RM, Marsh GM, Pariza MW, et al. Aspartame: a safety evaluation based on current use levels, regulations, and toxicological and epidemiological studies. Crit Rev Toxicol. 2007; 37(8):629-727.

15. Gallus S, Scotti L, Negri E, Talamini R, Franceschi S, Montella M, et al Artificial sweeteners and cancer risk in a network of case-control studies. Ann Oncol. 2007; 18(1):40-4.

16. Bosetti C, Gallus S, Talamini R, Montella M, Franceschi S, Negri E, et al. Artificial sweeteners and the risk of gastric, pancreatic, and endometrial cancers in Italy. Cancer Epidemiol Biomarkers Prev. 2009; 18(8):2235-8.

17. Elcock M, Morgan RW. Update on artificial sweeteners and bladder cancer. Regul Toxicol Pharmacol. 1993; 17(1):35-43.

18. Serra-Majem L, Bassas L, García-Glosas R, Ribas L, Inglés C, Casals I, et al. Cyclamate intake and cyclohexylamine excretion are not related to male fertility in humans. Food Addit Contam. 2003; 20(12):1097-104. 